\title{
Variabilidade isoenzimática em populações naturais de jacarandá paulista (Machaerium villosum Vog.)
}

\author{
MARIA CAROLINA G. BOTREL ${ }^{1}$ e DULCINÉIA DE CARVALHO ${ }^{1,2}$
}

(recebido: 26 de setembro de 2003; aceito: 24 de junho de 2004)

\begin{abstract}
Isozymes variability in natural populations of "jacarandá paulista" (Machaerium villosum Vog.)). In order to determine the variability levels among and within natural populations of Machaerium villosum, the genetic structure and the population effective size were analyzed by isozymes. Leaf tissues from three natural fragmented populations were sampled. Thirty-five individuals from the population 2 (Subestação) and thirty individuals from the population 1 (Matinha) and 3 (Bom Sucesso) were sampled. Twenty-six alleles distributed in 10 loci were identified in the populations studied. The estimated diversity index for the three populations revealed average of 2.4 of alleles per locus. The observed medium heterozigosity was higher than the expected for the three populations, revealing an excess of heterozygotes. The proportion of polymorphic loci was $90 \%$ in the populations 1 and 2 and $100 \%$ in the population 3 . The fixation index $(\hat{f})$ was negative to all populations. The genetic structure revealed on excess of heterozygotes for three populations $(\hat{F}=-0.121)$. The genetic divergence between the populations was relatively small $(0.061)$, revealing that $6.1 \%$ of the genetic variability found was between populations and 93.9\% was within the populations. The effective size estimated for all populations was 32, 48 and 42 individuals respectively. In order to ensure the genetic variability during seed collection twenty-one individuals must be sampled.
\end{abstract}

Key words - effective size, Fixation index, isozyme, polymorhism

RESUMO - (Variabilidade isoenzimática em populações naturais de jacarandá paulista (Machaerium villosum Vog.)). Com o intuito de determinar os níveis de variabilidade genética mantidos entre e dentro de populações, a estrutura genética e o tamanho efetivo populacional foram estudadas por meio da eletroforese de isoenzimas em populações naturais de Machaerium villosum. Foram amostrados tecidos foliares de três populações naturais fragmentadas, onde coletou-se 30 indivíduos adultos nas populações 1 e 3 (Matinha e Bom Sucesso) e 35 indivíduos na população 2 (Subestação). Foram identificados vinte seis alelos distribuídos em 10 locos. Os índices de diversidade estimados para as três populações revelaram média de 2,4 alelos por loco e heterozigosidade média observada maior que a esperada para as três populações, revelando um excesso de heterozigotos. O polimorfismo foi de $90,0 \%$ nas populações 1 e 2 e de $100 \%$ na população 3 . O índice de fixação $(\hat{f})$ foi negativo em todas populações. A estrutura genética revelou que há excesso de heterozigotos para o conjunto das populações $(\hat{F}=-0.121)$. A divergência genética entre as populações foi baixa (0,061), revelando que $6,1 \%$ da variabilidade genética encontram-se entre e 93,9\% dentro das populações. O tamanho efetivo estimado para cada população foi de 32, 48 e 42 indivíduos, respectivamente. Para a coleta de sementes, este parâmetro indicou a amostragem de 21 matrizes, de forma a garantir a manutenção da variabilidade genética.

Palavras-chave - Índice de fixação, isoenzimas, polimorfismo, tamanho efetivo

\section{Introdução}

A exploração inadequada dos recursos naturais vem provocando a extinção de um grande número de espécies nos diferentes biomas do planeta, especialmente naqueles situados nos trópicos. Entre as várias causas dessas extinções, as mais comuns são a perda e a fragmentação de hábitats. Em virtude de tal realidade, existe uma necessidade urgente de estudos genéticos ao nível populacional das espécies que compõem tais ecossistemas, pois pouco se sabe sobre as espécies ocorrentes, para que então possam ser estabelecidas

\footnotetext{
1. Universidade Federal de Lavras, Departamento de Ciências Florestais, Caixa Postal 37, 37200-000 Lavras, MG, Brasil.

2. Autor para correspondência: dulce@ufla.br
}

estratégias de manejo e conservação genética.

Poucas são as espécies estudadas do ponto de vista genético, sendo este tipo de estudo indispensável à conservação dos recursos da floresta tropical. Devido a restrições ao estudo de um grande número de espécies, tem-se procurado amostrar aquelas que o representem ou que sirvam de modelos para representar determinados biomas (Kageyama et al. 2003). Dentre essas, Machaerium villosum Vog, pertence à família Fabaceae, conhecido vulgarmente por Jacarandápaulista, demonstra ser adequada para o estudo da estrutura genética de populações por apresentar distribuição ampla, reprodução predominantemente alógama, dispersão anemocórica, polinização por abelhas e classifica-se entre os estágios finais da sucessão (Giudice Neto 1999). 
Considerando-se que no papel de reconstrução de florestas é importante que se mantenha o nível de variabilidade genética encontrado nas populações naturais, torna-se necessário, para a realização de um manejo florestal, estudos dos padrões de distribuição da variabilidade genética que ocorrem nos fragmentos florestais. Saber como essa variabilidade está partilhada dentro das populações é imprescindível, para que seus tamanhos não caiam abaixo do mínimo viável, comprometendo a perpetuação da espécie. Sendo assim, uma maneira muito utilizada para se conseguir detectar essa variabilidade é por meio de estudos da estrutura genética de populações naturais. Segundo Frankel (1983), o conhecimento dos níveis e da distribuição da variação genética dentro e entre populações torna-se pré-requisito para o estabelecimento de práticas conservacionistas efetivas e eficientes.

Uma ferramenta para esse tipo de estudo é a utilização da técnica de eletroforese de isoenzimas, que vem sendo muito utilizada na obtenção de informações em relação à quantificação da variabilidade genética em populações naturais.

Assim, no presente trabalho, três populações naturais de Machaerium villosum foram estudadas, a partir de eletroforese por isoenzimas, com o objetivo de quantificar a variabilidade genética entre e dentro de populações, visando a geração de subsídio para a adoção de estratégias de manejo e conservação genética.

\section{Material e métodos}

Neste estudo foram amostradas três populações naturais de Machaerium villosum localizadas em áreas distintas, no sul de Minas Gerais. A primeira população analisada encontra-se em um fragmento florestal, com área equivalente a 5,83 ha, localizado no campus da Universidade Federal de Lavras (UFLA), sendo conhecido como "Matinha da UFLA". O fragmento foi tombado como área de preservação permanente como Reserva Florestal da UFLA. Sua vegetação é classificada como Floresta Estacional Semidecidual Montana. A segunda população estudada, também localizada no campus da UFLA é um fragmento florestal que cobre uma área de 8,54 ha. A vegetação é classificada, fisionomicamente, como Floresta Estacional Semidecidual Montana, inserida no domínio da Mata Atlântica sensu lato (IBGE 1993, Veloso et al. 1991), sendo essa área escolhida devido ao seu bom estado de conservação. A terceira população está localizada na MG-335 que liga Macaia ao município de Bom Sucesso, com área de 2,5 ha aproximadamente, denominada Bom Sucesso. A primeira população está distante $1 \mathrm{~km}$ da segunda e $9 \mathrm{~km}$ da terceira e essa $8 \mathrm{~km}$ da segunda.

Foram analisados 95 indivíduos adultos nas três populações, sendo 35 na Subestação e 30 indivíduos nas populações da Matinha e Bom Sucesso. A amostragem foi aleatória ao longo dos três fragmentos, de forma a abranger toda área. Tecidos foliares de indivíduos reprodutivos foram coletados, sendo acondicionados em sacos plásticos devidamente identificados e colocados em caixa de isopor com gelo. Nas populações Matinha e Subestação as folhas foram coletadas no período de novembro e dezembro/2000 a janeiro/2001, enquanto em Bom Sucesso em julho/2001. Ao final de cada coleta, as folhas eram levadas para o Laboratório de Melhoramento Florestal e Recursos Genéticos (DCF-UFLA), sendo então armazenadas em freezer a $-18^{\circ} \mathrm{C}$, de modo a não permitir a degradação das enzimas.

O método de caracterização genética da espécie usado neste trabalho foi a eletroforese de isoenzimas, seguindo as técnicas mais comuns utilizadas, particularmente a metodologia descrita por Alfenas et al. (1991) e Alfenas (1998). Foram pesados $500 \mathrm{mg}$ de tecido foliar, estes foram limpos e macerados com areia lavada, adicionando-se $5 \mathrm{mg}$ de PVP-P e $1 \mathrm{~mL}$ da solução tampão de extração (tampão n.1 de Alfenas et al. 1991). A extração de enzimas foi realizada manualmente mediante ao uso de almofariz e pistilos de porcelana mantidos resfriadas durante o processo.

Foi utilizada eletroforese de isoenzimas vertical, conduzida em meio suporte de gel de poliacrilamida (concentração - 4\%, concentração - 12,5\%). Para a eletroforese foi utilizada amperagem de $10 \mathrm{~mA}$ por gel, 300 Volts, tendo a corrida eletroforética duração aproximada de 3,5 horas, sendo realizada à temperatura de $4^{\circ} \mathrm{C}$. As revelações dos géis foram baseadas na metodologia descrita por Alfenas (1998). Após o surgimento das bandas, os géis foram retirados da solução de revelação, lavados em água corrente e fixados em solução aquosa de glicerol a $10 \%$. A secagem dos géis foi efetuada no secador de gel (modelo 583, BioRad).

A interpretação dos zimogramas permitiu a obtenção dos genótipos de cada indivíduo, de modo a obter dados para a obtenção dos parâmetros de interesse. A identificação das zonas codificadoras dos locos e dos alelos foi feita a partir da região mais catódica para a mais anódica. Assim, em um sistema enzimático em que duas zonas de atividade eram claramente identificadas, a de maior migração no gel recebeu a denominação de loco-1 e a outra, loco-2. Da mesma forma, procedeu-se em relação aos alelos de cada loco. Realizada a genotipagem de cada indivíduo, foi possível estimar vários parâmetros que caracterizam a variabilidade genética entre e dentro das populações, a sua estrutura genética e o tamanho efetivo das populações. As frequiências alélicas descrevem a variação para um loco e foram estimadas pela contagem direta do número de alelos por loco, dividido pelo número total de alelos no loco: $\hat{P}_{i}=\mathrm{n}_{\mathrm{i}} / \mathrm{n}$ em que $\hat{P}_{i}$ é a freqüência do alelo $\mathrm{i}$, $\mathrm{n}_{\mathrm{i}}$ o número de ocorrência do alelo i e n o número total de alelos amostrados. A partir das freqüências alélicas foram estimados os índices de diversidade genética, tais como: heterozigosidade média observada $\left(\hat{H}_{o}\right)$, heterozigosidade média esperada $\left(\hat{H}_{e}\right)$, número médio de alelos por loco $(\mathrm{A})$; 
porcentagem de locos polimórficos $(\mathrm{P})$ e índices de fixação de Wright $(\hat{f})$, estimativas obtidas a partir do programa BIOSYS-2, desenvolvido por Swofford \& Selander (1989).

A estrutura genética foi abordada a partir dos coeficientes de coancestralidade de Cockerham (Cockerham 1969, Vencovsky 1992), obtidos a partir da decomposição dos componentes de variação da análise de variância das freqüências alélicas, conforme Cockerham (1969). A análise de variância foi realizada com a utilização do programa Genetic Data Analysis - GDA (Lewis \& Zaykin 2000).

O conhecimento do tamanho efetivo populacional $\left(\hat{N}_{e}\right)$ é imprescindível quando o objetivo é preservação de germoplasma, coleta de sementes e/ou conservação in situ, já que mede a representatividade genética dos indivíduos amostrados na população em relação a uma população panmítica ideal. Moraes (1997) ressalta que as estimativas dos tamanhos efetivos populacionais são indicadores instantâneos da representatividade genética das amostras. Portanto, fatores dinâmicos que afetam a distribuição das frequiências alélicas devem ser levados em consideração, tais como, flutuações do tamanho populacional entre gerações, variação de fertilidade entre os indivíduos, estrutura de idades e sobreposição de gerações e tamanho de vizinhança (Frankel et al. 1995).

Para se estimar o tamanho efetivo populacional, foram utilizados métodos propostos por Vencovsky (1997), para duas diferentes situações. A primeira estimativa do $\hat{N}_{e}$ para indivíduos adultos de uma simples população foi baseada na expressão $\hat{N}_{e}=n / 1+f$, onde $\mathrm{n}$ é o número de indivíduos e $f \mathrm{o}$ coeficiente de endogamia médio da população. A segunda estimativa do $\hat{N}_{e}$ para várias populações, baseada na expressão $\hat{N}_{e}=\frac{0,5}{\hat{\theta}_{p}\left(\frac{1+C_{p}}{m}-\frac{1}{n}\right)+\frac{1+F}{2 n}}$, onde:

$\hat{\theta}_{p}=$ divergência genética entre populações;

$m=$ número de populações avaliadas;

$n=$ número total de indivíduos avaliados nas populações $\left(n=\sum n_{i}\right)$

$C_{p}=$ quadrado do coeficiente de variação de $n_{i}$ sobre as populações $(i=1,2,3, \ldots, m)$;

$F=$ índice de fixação para o conjunto das populações.

\section{Resultados e Discussão}

Dos 21 sistemas enzimáticos (tabela 1) testados para o estabelecimento do protocolo para a espécie Machaerium villosum, foram escolhidos os seguintes: alfa-esterase $(\alpha$-EST), fosfatase ácida (ACP), glutamato oxaloacetato transaminase (GOT), peroxidase (PO) e malato desidrogenase (MDH) por apresentarem bandas polimórficas e passíveis de interpretação. As freqüências de 26 alelos de dez locos nas três populações naturais de Machaerium villosum são apresentadas na tabela 2. Houve uma grande variação
Tabela 1. Sistemas enzimáticos testados para Machaerium villosum Vog. E.C. $=$ Enzyme Commission.

Table 1. Enzymatic systems tested for Machaerium villosum Vog. E.C. $=$ Enzyme Commission.

\begin{tabular}{lcc}
\hline Enzima & Sigla & $\begin{array}{c}\text { Código } \\
\text { (E.C.) }\end{array}$ \\
\hline Álcool Desidrogenase & ADH & EC 1.1.1.1 \\
Catalase & CAT & EC 1.11.1.6 \\
Enzima Málica & ME & EC 1.1.1.40 \\
$\alpha$-Esterase & $\alpha$-EST & EC 3.1.1.1 \\
$\beta$-Esterase & $\beta$-EST & EC 3.1.1.1 \\
Fosfatase Alcalina & ALP & EC 3.1.3.1 \\
Fosfatase Ácida & ACP & EC 3.1.3.2 \\
Fosfoglucomutase & PGM & EC 2.7.5.1 \\
6-Fosfogluconato Desidrogenase & 6PGDH & EC 1.1.1.44 \\
Fosfoglucose Isomerase & PGI & EC 5.3.1.9 \\
$\beta$-Galactose Desidrogenase & $\beta$-GLDH & EC 1.1.1.48 \\
Glucose Desidrogenase & GLUDH & EC 1.1.1.47 \\
Glucose-6-Fosfato Desidrogenase & G6PDH & EC 1.1.1.49 \\
Glutamato Desidrogenase & GDH & EC 1.4.1.3 \\
Glutamato-Oxaloacetato & GOT & EC 2.6.1.1 \\
Leucina Aminopeptidase & LAP & EC 3.4.11.1 \\
Malato Desidrogenase & MDH & EC 1.1.1.37 \\
Peroxidase & PO & EC 1.11.1.7 \\
Sorbitol Desidrogenase & SDH & EC 1.1.1.14 \\
Superóxido Dismutase & SOD & EC 1.15.1.1 \\
Transaminase Isocitrato Desidrogenase IDH & EC 1.1.1.42 \\
\hline & &
\end{tabular}

nas freqüências alélicas nos indivíduos analisados, desde a fixação de alelos até freqüências muito baixas. Nos indivíduos da população Subestação foi encontrada baixa frequiência para o alelo 2 do loco Got-1 $(0,060)$ e ausência para o alelo 3 do loco $\alpha$-Est 1, alelo 3 do loco Po 1, alelo 2 do loco Mdh 1 e alelo 3 do loco Mdh 3. Na população Matinha, os alelos que apresentaram baixas freqüências foram: alelo 3 dos locos $\alpha$-Est 1 e Po 1 (0,052 e 0,017). Ausências foram observadas para o alelo 2 do loco Mdh 1, alelo 3 do loco Mdh 3. Com relação à população Bom Sucesso, baixas frequiências ocorreram nos alelos 3 dos locos $\alpha$-Est $1(0,056), \alpha$-Est $2(0,045)$, Acp $1(0,037)$, Po $1(0,052)$ e Mdh $3(0,042)$. Houve a fixação do alelo 1 da Mdh 1 nas populações Subestação e Matinha e em Bom Sucesso não se verificou fixação de alelos.

Alterações nas freqüências alélicas entre populações podem ser indicativos de deriva genética. Essas alterações podem também ser devido à migração, que altera as frequiências alélicas na população pela introdução de alelos advindos de outras populações. A migração de alelos pode ser evidenciada pela presença de alelos raros a uma das populações analisadas. A 
análise das freqüências alélicas é de grande importância, pois reflete os efeitos estocásticos mais adequadamente que a maioria dos parâmetros utilizados no estudo de genética de populações, uma vez que, alguns parâmetros como a heterozigosidade observada, não refletem

Tabela 2. Frequiências alélicas e tamanho da amostra (n) em 10 locos aloenzimáticos em três populações naturais de Machaerium villosum Vog.

Table 2. Alleles frequency and sample size (n) in 10 allozyme loci in three natural populations of Machaerium villosum Vog.

\begin{tabular}{|c|c|c|c|c|}
\hline \multirow[b]{2}{*}{ Loco } & \multicolumn{4}{|c|}{ Populações } \\
\hline & Alelo & Matinha & Subestação & Bom Sucesso \\
\hline \multirow[t]{4}{*}{$\alpha$ - Est- 1} & 1 & 0,241 & 0,456 & 0,593 \\
\hline & 2 & 0,707 & 0,544 & 0,3552 \\
\hline & 3 & 0,052 & 0,000 & 0,056 \\
\hline & $\mathrm{n}$ & 29 & 34 & 27 \\
\hline \multirow[t]{4}{*}{$\alpha-$ Est-2 } & 1 & 0,500 & 0,317 & 0,591 \\
\hline & 2 & 0,313 & 0,317 & 0,364 \\
\hline & 3 & 0,188 & 0,367 & 0,045 \\
\hline & $\mathrm{n}$ & 24 & 30 & 22 \\
\hline \multirow[t]{4}{*}{ Acp-1 } & 1 & 0,333 & 0,443 & 0,500 \\
\hline & 2 & 0,483 & 0,400 & 0,463 \\
\hline & 3 & 0,183 & 0,157 & 0,037 \\
\hline & $\mathrm{n}$ & 30 & 35 & 27 \\
\hline \multirow[t]{3}{*}{ Acp-2 } & 1 & 0,683 & 0,686 & 0,536 \\
\hline & 2 & 0,317 & 0,314 & 0,464 \\
\hline & $\mathrm{n}$ & 30 & 35 & 28 \\
\hline \multirow[t]{4}{*}{ Got-1 } & 1 & 0,517 & 0,520 & 0,375 \\
\hline & 2 & 0,276 & 0,060 & 0,214 \\
\hline & 3 & 0,207 & 0,420 & 0,411 \\
\hline & $\mathrm{n}$ & 29 & 25 & 28 \\
\hline \multirow[t]{3}{*}{ Got-2 } & 1 & 0,518 & 0,760 & 0,464 \\
\hline & 2 & 0,482 & 0,240 & 0,536 \\
\hline & $\mathrm{n}$ & 28 & 25 & 28 \\
\hline \multirow[t]{4}{*}{ Po-1 } & 1 & 0,367 & 0,400 & 0,414 \\
\hline & 2 & 0,617 & 0,600 & 0,534 \\
\hline & 3 & 0,017 & 0,000 & 0,052 \\
\hline & $\mathrm{n}$ & 30 & 35 & 29 \\
\hline \multirow[t]{3}{*}{ Mdh-1 } & 1 & 1,000 & 1,000 & 0,483 \\
\hline & 2 & 0,000 & 0,000 & 0,517 \\
\hline & $\mathrm{n}$ & 35 & 30 & 29 \\
\hline \multirow[t]{3}{*}{ Mdh-2 } & 1 & 0,683 & 0,671 & 0,534 \\
\hline & 2 & 0,317 & 0,329 & 0,466 \\
\hline & $\mathrm{n}$ & 30 & 35 & 29 \\
\hline \multirow[t]{4}{*}{ Mdh-3 } & 1 & 0,383 & 0,273 & 0,479 \\
\hline & 2 & 0,617 & 0,727 & 0,479 \\
\hline & 3 & 0,000 & 0,000 & 0,042 \\
\hline & $\mathrm{n}$ & 30 & 33 & 24 \\
\hline Total de alelos & s 26 & 24 & 22 & 26 \\
\hline
\end{tabular}

diretamente freqüências alélicas eventualmente muito baixas. Souza (1997) concluiu que para Chorisia speciosa A.St.-Hil. os parâmetros comumente utilizados para a caracterização da variabilidade genética $\left(H_{o}, H_{e}\right.$, $P$ e $A$ ) muitas vezes não conseguem mostrar perda de alelos, não sendo bons indicadores de deriva genética, sendo indicado então a análise direta dos dados de frequiência alélica.

Os parâmetros estimados a partir das frequiências alélicas de dez locos isoenzimáticos para avaliar a variabilidade genética estão apresentados na tabela 3 . A porcentagem de locos polimórficos $(\hat{P})$ foi de $90,0 \%$ para duas populações, Subestação e Matinha, enquanto para população de Bom Sucesso essa porcentagem foi de $100 \%$. Comparando-se a espécie estudada com outras, observa-se que esta possui valores de $\hat{P}$ próximos ao encontrado em Eucalyptus urophylla (77,8\%) estudada por Corder et al. (1996), superiores aos encontrados por Kawaguici \& Kageyama (2001) em Calophyllum brasiliense (42,86\%) e em Genipa americana no estudo realizado por Sebbenn et al. (1998) onde $\hat{P}$ foi 50\%. Giudice Neto (1999), estudando essa mesma espécie, $M$. villosum, observou valores de $\hat{P}$ bem semelhantes, variando de $90 \%$ a $100 \%$. Os resultados obtidos pela análise da porcentagem de locos polimórficos mostram que $M$. villosum apresenta um alto polimorfismo, o que torna estas populações favoráveis à conservação genética. Em relação ao número de alelos por loco, houve valores médios iguais a 2,2 (Subestação), 2,4 (Matinha) e 2,6 (Bom Sucesso), valores não diferentes entre si, a julgar pelo desvio padrão.

As heterozigosidades médias observadas foram maiores que as esperadas em todas as populações de M. villosum, evidenciando uma tendência de excesso de heterozigotos em relação ao EHW. O índice de fixação de cada população foi negativo e alto, sendo $-0,068$ para Matinha, $-0,285$ para a Subestação e $-0,287$ para Bom Sucesso, sugerindo que esteja ocorrendo seleção para heterozigotos nestas populações. Lacerda et al. (1999), estudando duas populações de Myracrodruon urundeuva, observaram valores próximos $(-0,333$ e $-0,301)$ aos encontrados para M. villosum

O termo estrutura genética de populações, será aqui utilizado como sinônimo da distribuição da variabilidade genética entre e dentro de populações. Na tabela 4 são apresentados os coeficientes de coancestralidade do Cockerham (Cockerham 1969, Vencovsky 1992) para as três populações de $M$. villosum, onde $\hat{f}$ é o índice de fixação médio dentro das populações, $\hat{F}$ é o índice de 
Tabela 3. Índices de diversidade genética de três populações naturais de Machaerium villosum Vog., baseados em 10 locos e 5 sistemas enzimáticos. Os valores entre parênteses equivalem ao erro padrão.

Table 3. Indexes of genetic diversity of three populations of Machaerium villosum Vog., determined by 10 loci and five isozymes systems. ( ) = standard error.

\begin{tabular}{|c|c|c|c|}
\hline \multirow{2}{*}{$\begin{array}{l}\text { Ìndices de diversidade } \\
\text { genética }\end{array}$} & \multicolumn{3}{|c|}{ Populações } \\
\hline & Matinha & Subestação & Bom Sucesso \\
\hline $\begin{array}{l}\text { Tamanho médio da } \\
\text { amostra por loco }(n)\end{array}$ & 28,90 & 32,45 & 27,10 \\
\hline $\begin{array}{l}\text { Número médio de } \\
\text { alelos por locos }(A)\end{array}$ & $\begin{array}{c}2,4 \\
(0,2)\end{array}$ & $\begin{array}{c}2,2 \\
(0,2)\end{array}$ & $\begin{array}{c}2,6 \\
(0,2)\end{array}$ \\
\hline $\begin{array}{l}\text { Porcentagem de locos } \\
\text { polimórficos }(\hat{P})\end{array}$ & 90,0 & 90,0 & 100,0 \\
\hline $\begin{array}{l}\text { Heterozigosidade média } \\
\text { observada }\left(\hat{H}_{o}\right)\end{array}$ & $\begin{array}{c}0,501 \\
(0,078)\end{array}$ & $\begin{array}{c}0,581 \\
(0,081)\end{array}$ & $\begin{array}{c}0,694 \\
(0,093)\end{array}$ \\
\hline $\begin{array}{l}\text { Heterozigosidade média } \\
\text { esperada }\left(\hat{H}_{e}\right)\end{array}$ & $\begin{array}{c}0,469 \\
(0,058)\end{array}$ & $\begin{array}{c}0,452 \\
(0,059)\end{array}$ & $\begin{array}{c}0,539 \\
(0,014)\end{array}$ \\
\hline Índice de Fixação $(\hat{f})$ & $-0,068$ & $-0,285$ & $-0,287$ \\
\hline
\end{tabular}

fixação para o conjunto das populações, $\hat{\theta}_{P}$ é a divergência genética entre populações. Estes parâmetros são correspondentes às estimativas $\hat{F}_{I S}, \hat{F}_{I T}$ e $\hat{F}_{S T}$ de Wright (1951). A estimativa da endogamia para o conjunto das populações $(\hat{F}=-0,121)$ indica excesso de heterozigotos. A estimativa da endogamia média dentro das populações $(\hat{f})$ mostra alta heterozigose $(-0,194)$; isto sugere que, em média, as populações não são endogâmicas.

A divergência genética entre populações $\left(\hat{\theta}_{P}\right)$ foi relativamente baixa $(0,061)$, isto significa que $6,1 \%$ da

Tabela 4. Índices de fixação e coeficiente de coancestralidade entre três populações de indivíduos adultos de Machaerium villosum Vog. Valores entre colchetes equivalem aos intervalos de confiança.

Table 4. Fixation index and coancestry coefficient among three populations of Machaerium villosum Vog. [ ] = confidence interval.

\begin{tabular}{lc}
\hline Parâmetros & Estimativas \\
\hline $\begin{array}{l}\text { Índice de fixação médio dentro } \\
\text { das populações }(\hat{f})\end{array}$ & $-0,194[-0,41$ a - 0,035$]$ \\
$\begin{array}{l}\text { Indice de fixação para o conjunto } \\
\text { das populações }(\hat{F})\end{array}$ & $-0,121[-0,31$ a 0,055$]$ \\
$\begin{array}{l}\text { Divergência genética entre } \\
\text { as populações }\left(\hat{\theta}_{P}\right)\end{array}$ & $0,061[0,02$ a 0,133$]$ \\
\hline
\end{tabular}

variabilidade genética encontra-se entre e que 93,9\% desta, encontra-se dentro das populações. Kageyama et al. (2003) também observaram uma baixa divergência genética entre as populações de Ocotea odorifera, onde encontrou um $\hat{\theta}_{P}$ de 0,028 , mostrando que a maior diversidade se encontra dentro das populações.

As populações, no presente estudo, apresentaram variabilidade genética alta dentro e baixa entre populações. Segundo Loveless \& Hamrick (1984), as espécies tipicamente alógamas apresentam variabilidade genética alta dentro de populações. A divergência entre populações é reduzida com o aumento do fluxo gênico (pólen e/ou sementes).

A análise da estrutura genética em cada par de população (tabela 5), mostrou baixa divergência entre as mesmas. Os maiores valores foram encontrados para as populações Matinha Bom e Sucesso $(0,075)$ e Subestação e Bom Sucesso $(0,089)$ quando comparadas às populações da Matinha e Subestação $(0,022)$. Isto indica que as populações da Matinha e Subestação são mais similares entre si e divergentes da população de Bom Sucesso. Este resultado é coerente, visto que essas duas populações se encontram geograficamente mais próximas $(1 \mathrm{~km})$. No entanto, sabendo que a espécie em estudo apresenta dispersão anemocórica, baseado na forma, estrutura e dimensão dos propágulos que permitem a dispersão das sementes pelo vento, acredita-se que este quadro pode se alterar no futuro.

Tabela 5. Divergência genética $\left(\hat{\theta}_{P}\right)$ para pares de populações. Valores entre colchetes correspondem aos intervalos de confiança.

Table 5 . Genetic diversity $\left(\hat{\theta}_{P}\right)$ between the populations. [ ] = confidence interval

\begin{tabular}{lc}
\hline Populações & $\hat{\theta}_{P}$ \\
\hline Matinha e Sub estação & $0,022[0,0020 \mathrm{a} 0,045]$ \\
Matinha e Bom Sucesso & $0,075[0,0120 \mathrm{a} 0,173]$ \\
Sub estação e Bom Sucesso & $0,089[0,0281$ a 0,180$]$ \\
\hline
\end{tabular}

A partir da estimativa de $\hat{N}_{e}$ (tabela 6) pode-se pressupor que os 30 indivíduos adultos amostrados na população da Matinha, os 35 na Subestação e os $30 \mathrm{em}$ Bom Sucesso, representariam geneticamente 32, 49 e 42 indivíduos, respectivamente, de uma população panmítica ideal. Os valores de $\hat{N}_{e}$ reafirmam a existência de baixa endogamia nas populações estudadas já que os tamanhos efetivos calculados para cada uma das populações foi superior ao número de indivíduos 
Tabela 6. Tamanho efetivo $\left(\hat{N}_{e}\right)$ e número de indivíduos (n) de três populações naturais de Machaerium villosum a partir de dados de indivíduos adultos das populações.

Table 6. Effective size $\left(\hat{N}_{e}\right)$ and individuals number (n) in three natural populations of Machaerium villosum.

\begin{tabular}{lcc}
\hline População & $\mathrm{n}$ & $\hat{N}_{e}$ \\
\hline Matinha & 30 & 32 \\
Sub estação & 35 & 49 \\
Bom Sucesso & 30 & 42 \\
Conjunto das populações & 95 & 21 \\
\hline
\end{tabular}

amostrados. Os heterozigotos, por carregarem sempre dois alelos distintos, representam um maior número de indivíduos na população e em todas para as populações analisadas, foi observada alta heterozigosidade.

Vencovsky (1987) afirma que, para a maximização das atividades de coleta de sementes, é importante ter informações a respeito da representatividade genética das matrizes da população, podendo então ser calculado o número de matrizes a serem amostradas. $\mathrm{O}$ mesmo autor sugere que, para a coleta de sementes e conservação de germoplasma, o aumento do $\hat{N}_{e}$ seja feito por meio do controle gamético feminino, coletando se igual número de sementes de cada planta matriz. Esta prática resulta em igual contribuição de gametas femininos, já que é excluído o risco de contribuição desigual entre matrizes, redução da deriva genética e conseqüente aumento do tamanho efetivo. Portanto, a amostragem deve ser aleatória não nas sementes, e sim nas matrizes, tomando-se o cuidado de amostrar igual número de sementes do maior número possível de plantas genitoras.

Então, para a coleta de sementes de M. villosum, recomenda-se amostragem em pelo menos 21 árvores matrizes (tabela 6), para que se garanta a manutenção da variabilidade genética nas sementes. No enriquecimento da vegetação ou recuperação de áreas, a coleta de sementes a partir deste princípio proporcionará infinitas novas recombinações genotípicas na população, elevando seu potencial evolutivo. As informações obtidas deste estudo nos auxiliarão em projetos de manejo e conservação genética de M. villosum.

Agradecimentos - Expressamos a nossa gratidão ao CNPq pela bolsa de Iniciação Científica concedida ao primeiro autor e pela bolsa de Produtividade concedida ao segundo autor (Proc. n. 300542/89-5).

\section{Referências bibliográficas}

ALFENAS, A.C. 1998. Eletroforese de isoenzimas e proteínas afins: fundamentos e aplicações em plantas e microrganismos. Universidade Federal de Viçosa, Viçosa.

ALFENAS, A.C., PETERS, I., BRUNE, W. \& PASSADOR, G.C. 1991. Eletroforese de proteínas e isoenzimas de fungos e essências florestais. Universidade Federal de Viçosa, Viçosa.

COCKERHAM, C.C. 1969. Variance of gene frequencies. Evolution 23:72-84.

CORDER,M.P.M.,MORI,E.S., KAGEYAMA,P.Y.\&LOPES, C.R. 1996. Estudo da Variabilidade isoenzimática em Eucalyptus urophylla das ilhas flores. Scientia Forestalis 50:43-49.

FRANKEL, O.H. 1983. The place of management in conservation. In Genetics and conservation: a reference for managing wild animal and plant populations. (C.M. Schonewaldcox, S.M. Chambers, B. MacBryde \& W.L. Thomas, eds.). The Benjamin/Cumming Pub. Company, Menlo Park, p.1-14.

FRANKEL, O.H., BROWN, A.H.D. \& BURDON, J.J. 1995. The conservation of plant biodiversity. Cambrigde University Press, Cambrigde.

GIUDICE NETO, J.D. 1999. Estrutura genética por isoenzimas em populações naturais de Jacarnadá Paulista (Macherium villosum Vog.). Dissertação de mestrado, Escola Superior de Agricultura "Luiz de Queiroz", Piracicaba.

IBGE. 1993. Mapa de vegetação do Brasil, Fundação Instituto Brasileiro de Geografia e Estatística, Rio de Janeiro.

KAGEYAMA, P.Y., SEBBENN, A.M., RIBAS, L.A., GANDARA, F.B. CASTELLEN, M., PERECIM, M.B. \& VENCOVSKY, R. 2003. Diversidade genética em espécies tropicais de diferentes estágios sucessionais por marcadores genéticos. Scientia Forestalis 64:93-107.

KAGEYAMA, P.Y., CUNHA, G.C., BARRETO, K.D., GANDARA, F.B., CAMARGO, F.R.A. \& SEBBENN, A.M. 2003. Diversidade e autocorrelação genética espacial em populações de Ocotea odorifera (Lauraceae). Scientia Forestalis 64:108-119.

KAWAGUICI, C.B. \& KAGEYAMA, P.Y. 2001. Diversidade genética de três grupos de indivíduos (adultos, jovens e plântulas) de Calophyllum brasiliense em uma população de mata de galeria. Scientia Forestalis 59:131-143.

LACERDA, C.M.B., KAGEYAMA, P.Y. \& FERRAZ, E.M. 1999. Diversidade isoenzimática em Myracrodruon urundeuva em duas situações antrópicas no semi-árido. Scientia Forestalis 55:89-95.

LEWIS, P.O. \& ZAYKIN, D. 2000. Genetic Data Analysis: Computer program for the analysis of allelic data. Version 1.0 (d15). Free program distributed by the authors over the internet from the GDA Home Page at http: // alleyn.eeb.uconn.edu/gda/2000 (acesso em 11/09/2002).

LOVELESS, M.D. \& HAMRICK, J.L. 1984. Ecological determinants of genetic structure in plant populations. Annual Review of Ecology and Systematics 15:65-95. 
MORAES, P.L.R. 1997. Estrutura genética de população de Cryptocarya moschata Nees e Martius ex Nees (Lauraceae). Tese de doutorado, Universidade Estadual de São Paulo, Rio Claro.

SEBBENN, A.M., KAGEYAMA, P.Y. \& VENCOVSKY, R. 1998. Variabilidade genética, sistema reprodutivo e estrutura genética espacial em Genipa americana $\mathrm{L}$. através de marcadores isoenzimáticos. Scientia Forestalis 53:15-30.

SOUZA, L.M.F.I. 1997. Estrutura genética de populações naturais de Chorisia speciosa St. Hil. (Bombacaceae) em fragmentos florestais na região de Bauru (SP) - Brasil. Tese de doutorado, Escola Superior de Agricultura "Luiz de Queiroz", Piracicaba.

SWOFORD, D.L. \& SELANDER, R.B. 1989. BIOSYS 1: A computer program for the analysis of allelic variation in population genetics and biochemical systematics. Release 1.7. Natural History Survey, Illinois.
VELOSO, H.P., RANGEL FILHO, A.L.R. \& LIMA, J.C.A. 1991. Classificação da Vegetação Brasileira. Adaptada a um Sistema Universal. Instituto Brasileiro de Geografia e Estatística, Rio de Janeiro.

VENCOVSKY, R. 1987. Tamanho efetivo populacional na coleta e preservação de germoplasma de espécies alógamas. Revista IPEF 35:79-84.

VENCOVSKY, R. 1992. Análise de Variância de Frequiências Alélicas. Revista Brasileira de Genética 15:53-60.

VENCOVSKY, R. 1997. Biometrical approaches for molecular markers estimation of effective population size. In Proceedings of the International Workshop on Agricultural Biotechnology. Esalq/USP, Piracicaba, p.233-234.

WRIGHT, S. 1951. The genetical structure of populations. Annual of Eugenics 15:313-354. 
